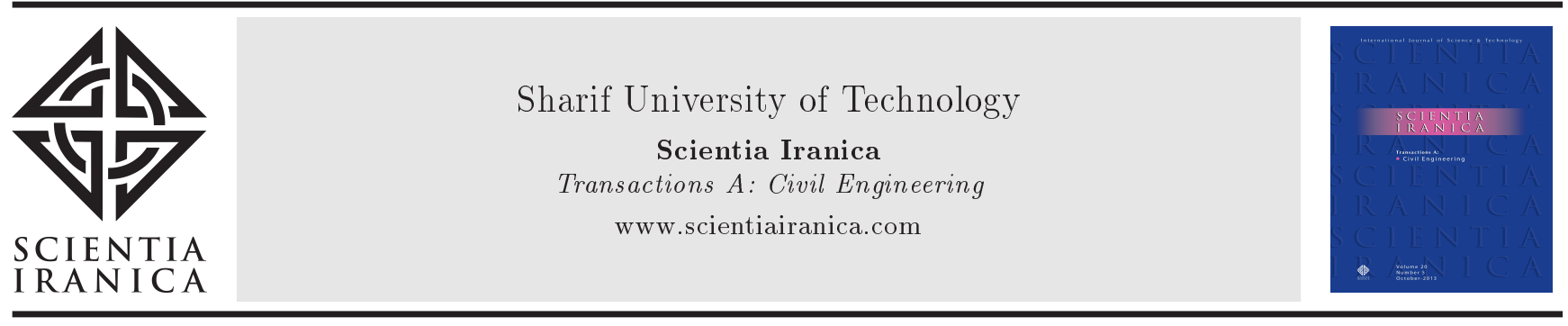

\title{
Axisymmetric active lateral earth pressure for $c-\phi$ soils using the stress characteristics method
}

\author{
A. Keshavarz* and M. Ebrahimi \\ School of Engineering, Persian Gulf University, Bushehr, Iran.
}

Received 11 December 2015; received in revised form 7 May 2016; accepted 18 June 2016

\section{KEYWORDS}

Lateral earth pressure; Axisymmetric;

Stress characteristics;

Slip lines;

Finite element.

\begin{abstract}
The slip line or Stress Characteristics Method (SCM) is used to analyze the active lateral earth pressure in the axisymmetric case. In this paper, in addition to the retaining walls in the axisymmetric and plane strain conditions that were studied in the past, a new model of the retaining wall in the axial symmetry is considered, which can be widely used in the design of grain silos, buildings, and road constructions. The effects of various parameters, including cohesion and friction angle of the soil, wall and backfill slopes, soil-wall interface adhesion, and friction angle, on the lateral earth pressure have been evaluated for all cases of the retaining walls. Based on the proposed theory, a computer code has been developed for the plane strain and axisymmetric cases. Also, finite element modelling is used to verify the results of the SCM. Comparison of the results indicates the accuracy of the proposed method. Furthermore, the effect of the plastic critical or tension crack depth has been evaluated and it is indicated that neglecting the plastic critical depth is not conservative.
\end{abstract}

(C) 2017 Sharif University of Technology. All rights reserved.

\section{Introduction}

Active lateral earth pressure plays an important role in the design of geotechnical structures. The theories developed by Coulomb [1] and Rankine [2] are of the most basic methods for the analysis of the lateral earth pressure. Coulomb [1] assumed a planar failure surface and presented a limit equilibrium method for estimating the lateral earth pressure of granular soils. Terzaghi [3] provided a graphical solution for lateral earth pressure problems in cohesive backfill. Mazindrani and Ganjali [4] presented an analytical solution for the lateral pressure problems in cohesive backfill and provided some tables for the active and passive lateral earth pressure coefficients for vertical wall and

*. Corresponding author. Tel./Fax: +98 rr33440376 E-mail addresses: keshavarz@pgu.ac.ir (A. Keshavarz); mohsenebrahimi01@gmail.com (M. Ebrahimi) cohesive sloping backfill. Gnanapragasam [5] developed an analytical method to determine the distribution of the active lateral earth pressure on vertical retaining wall with cohesive-frictional sloping backfill. She considered the plastic critical depth in the solution. Furthermore, many other researchers have studied the active lateral earth pressure problem [6-8].

The stress characteristics or slip line method was proposed by Sokolovski $[9,10]$. This method has been applied in many geotechnical problems, including bearing capacity of foundations [11-16] and the active and passive lateral earth pressure [17-20]. Kumar and Chitikela [18] used the SCM to estimate the seismic passive lateral earth pressure. Cheng [17] and Peng and Chen [21] used the method of characteristics for estimating the static and seismic lateral earth pressure. Keshavarz [22] employed this method to evaluate the plastic critical depth in seismic case.

There are many axisymmetric problems in geotechnical engineering, including circular and ring foundations and circular excavations. Berezantzev [23] 
and Cheng et al. [24] developed simplified slip line analytical solution for active lateral earth pressure on circular retaining walls with horizontal c- $\phi$ backfill without considering wall friction. Liu et al. [25] investigated the axisymmetric active lateral earth pressure for layered c- $\phi$ backfill. Cheng et al. [26], Liu and Wang [27], and Liu et al. [28] employed SCM to calculate the active lateral earth pressure on circular retaining wall. Liu [29] extended the method of characteristics to solve the axisymmetric active lateral earth pressure for homogenous or layered backfill considering wall movement.

In this paper, in addition to the circular retaining wall that has been studied by previous researchers (inward wall, Figure 1(a)), another type of the retaining wall has also been investigated (outward wall, Figure 1(b)). As seen in Figure 1, inward wall is similar to a circular excavation. However, in outward wall, the axis of symmetry is located on the soil mass. Outward retaining wall is widely constructed in the grain silos, roads, piers, and other geotechnical structures. In addition, in this paper, the effect of the soil-wall interface adhesion in axisymmetric case is considered, which has not been taken into account in the previous studies.

Written computer code can calculate the lateral earth pressure in both the axisymmetric and plane
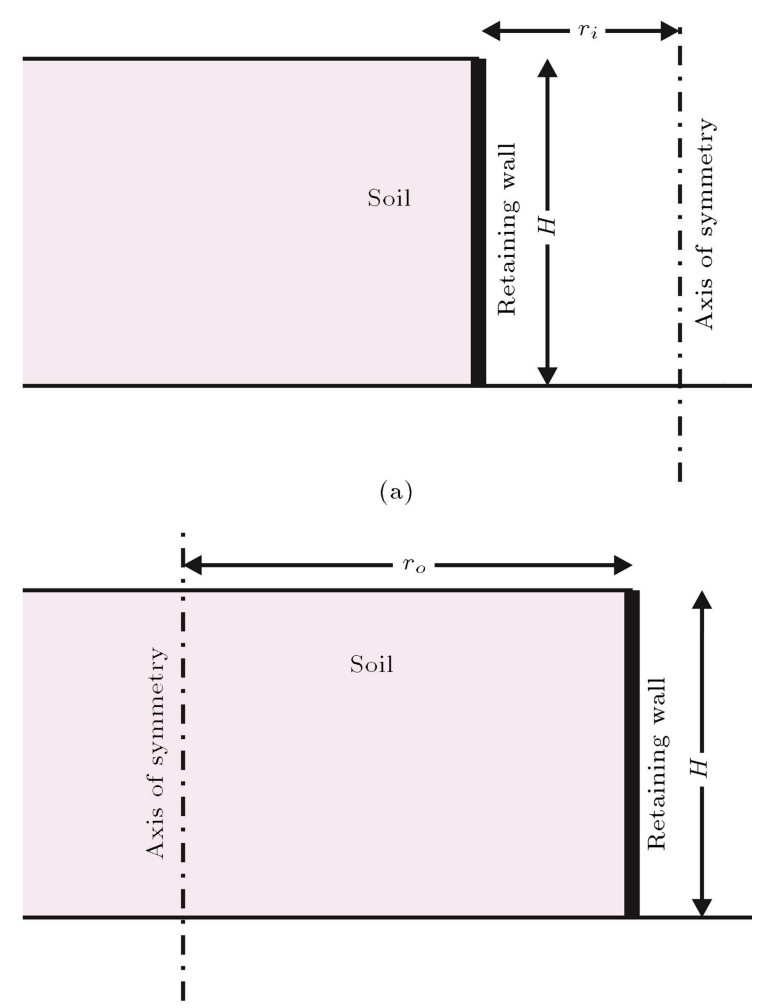

(b)

Figure 1. The models of the rigid retaining wall in the axisymmetric condition: (a) Inward wall and (b) outward wall. strain cases. In this study, the effects of parameters such as backfill slope, wall inclination, soil friction angle and cohesion, and soil-wall interface friction and adhesion on the distribution of the stress on the retaining wall are investigated. The results of this study have been compared with those of previous works as well as the results of the finite element method constructed in this paper. In addition, unlike the previous works, the effect of the plastic critical depth on the axisymmetric active lateral earth pressure is investigated.

\section{Theory}

\subsection{Stress equilibrium equations}

Axisymmetric conditions are assumed for soil in $r-z$ plane. Stress equilibrium equations are [30]:

$$
\begin{aligned}
& \frac{\partial \sigma_{r}}{\partial r}+\frac{\partial \tau_{r z}}{\partial z}=f_{r}, \\
& \frac{\partial \sigma_{r}}{\partial z}+\frac{\partial \tau_{r z}}{\partial r}=f_{z},
\end{aligned}
$$

where:

$$
\begin{aligned}
f_{r} & =-\frac{n}{r}\left(\sigma_{r}-\sigma_{\theta}\right), \\
f_{z} & =-\gamma-\frac{n}{r} \tau_{r z} .
\end{aligned}
$$

$\gamma$ represents the unit weight of the soil, and $n$ is equal to 0 and 1 in the plane strain and axisymmetric cases, respectively. The value of $\sigma_{\theta}$ is equal to $\lambda \sigma_{1}$ for the inward retaining wall (Figure $1(\mathrm{a})$ ) and is equal to $\lambda \sigma_{3}$ for the outward retaining wall (Figure $1(\mathrm{~b})$ ), where, $\sigma_{1}$ and $\sigma_{3}$ are the major and minor principle stresses, respectively. Berezantzev [23] and Liu and Wang [27] used Harr-von Karman's hypothesis [31] $(\lambda=1)$ for the axisymmetric problems. The Haar-von Karman method [31] has been widely applied in axisymmetric problems. There is no evidence indicating the actual state of the intermediate principal stress and, in fact, there is always a lack of information about the circumferential stress; however, to keep it always within an admissible range, one should choose either the minor or the major principal stress (or something between). In addition, it should be noted that the Mohr-Coulomb failure criterion is not a fully $3 \mathrm{D}$ criterion and, hence, the intermediate principal stress does not affect the state of the yield within a radial plane; it is only used to properly solve the stress field. Also, the results of the experimental study and DEM (discrete element method) [32,33] demonstrate a good agreement with the solutions obtained using Harr-Karman's hypothesis such as Terzaghi [3] and Berezantzev [23]. Therefore, in this study, the Harr-Karman's hypothesis is used. 
If in the Mohr circle of stress, the average stress and the angle between $r$-axis and the direction of major principal stress $\left(\sigma_{1}\right)$ are denoted by $p$ and $\psi$, respectively, then stress components can be written as:

$$
\begin{aligned}
& \sigma_{r}=p(1+\sin \phi \cos 2 \psi)+c \cos \phi \cos 2 \psi, \\
& \sigma_{z}=p(1-\sin \phi \cos 2 \psi)-c \cos \phi \cos 2 \psi, \\
& \tau_{r z}=(p \sin \phi+c \cos \phi) \sin 2 \psi,
\end{aligned}
$$

where $c$ and $\phi$ are the cohesion and friction angle of the soil, respectively. Taking the derivatives of Eq. (3), substituting them in Eq. (1), and simplifying it, two sets of equilibrium equations can be found on each of the plus and minus stress characteristics [30]:

Along the plus characteristic, $\sigma^{+}$:

$$
\begin{aligned}
& \frac{\mathrm{d} z}{\mathrm{~d} r}=\tan (\psi+\zeta) \\
& \mathrm{d} p+2(p \tan \phi+c) \mathrm{d} \psi=f_{r}(\mathrm{~d} r-\tan \phi \mathrm{d} z) \\
& \quad+f_{z}(\tan \phi \mathrm{d} r+\mathrm{d} z) .
\end{aligned}
$$

And along the minus characteristic, $\sigma^{-}$:

$$
\begin{aligned}
& \frac{\mathrm{d} z}{\mathrm{~d} r}=\tan (\psi-\zeta) \\
& \mathrm{d} p-2(p \tan \phi+c) \mathrm{d} \psi=f_{r}(\mathrm{~d} r+\tan \phi \mathrm{d} z) \\
& \quad+f_{z}(-\tan \phi \mathrm{d} r+d z),
\end{aligned}
$$

where $\zeta$ is the angle between the characteristic lines and the direction of the major principal stress, $\zeta=$ $\pi / 4-\phi / 2$ (Figure 2).

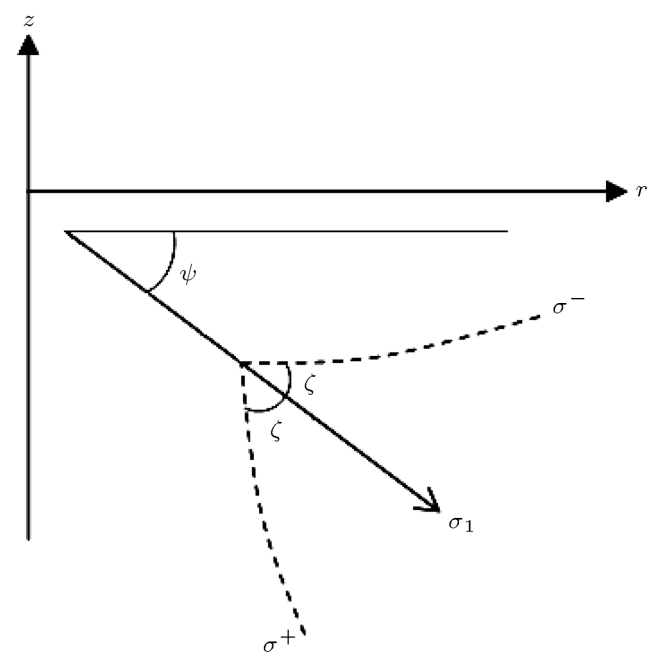

Figure 2. Orientation of the plus and minus characteristics with respect to $r$ and $z$ axes.

\subsection{Boundary conditions}

The boundary conditions on the ground surface and soil-wall interface are required in the stress characteristics method. The geometry of the problem is shown in Figure 3. The vertical surcharge, $q$, is exerted to the ground surface. $\beta$ is the slope of the backfill and $\theta$ represents the angle between the wall and the $z$ axis. As shown in Figure 3, $\beta$ and $\theta$ are positive in counterclockwise direction. The soil-wall interface friction angle and adhesion are denoted by $\delta_{w}$ and $c_{w}$, respectively.

At the ground boundary (OD), $r$ and $z$ are known whereas $p$ and $\psi$ are unknown. The normal and shear stresses on the ground boundary are obtained as:

$$
\begin{aligned}
\sigma_{0} & =q \cos ^{2} \beta, \\
\tau_{0} & =q \cos \beta \sin \beta .
\end{aligned}
$$

Using the Mohr's circle of stress, $p_{0}$ and $\psi_{0}$ on the ground surface can be calculated by:

$$
\begin{aligned}
& p_{0}= \\
& \frac{\sigma_{0}+c \cos \phi \sin \phi-\sqrt{\left(\sigma_{0} \sin \phi+c \cos \phi\right)^{2}-\left(\tau_{0} \cos ^{2} \phi\right)^{2}}}{\cos ^{2} \phi}, \\
& \psi_{0}=\frac{\pi}{2}+0.5\left(\beta-\sin ^{-1}\left(\frac{p_{0} \sin \beta}{p_{0} \sin \phi+c \cos \phi}\right)\right) \\
& \quad \text { if } q \neq 0 \\
& \psi_{0}=\frac{\pi}{2}+\beta \quad \text { if } q=0 .
\end{aligned}
$$

At the wall boundary (OA), $r, z, p$, and $\psi$ are unknown, but the relation between $r$ and $z$ is known. The $\psi_{f}$ on the wall is obtained as:

$$
\begin{aligned}
\psi_{f}= & \frac{\pi}{2}+\theta+0.5\left(-\delta_{w}\right. \\
& \left.+\sin ^{-1}\left(\frac{p_{f} \sin \delta_{w}+c_{w} \cos \delta_{w}}{p_{f} \sin \phi+c \cos \phi}\right)\right) .
\end{aligned}
$$

\subsection{Analysis procedure}

The method of analysis is similar to that used in the conventional stress characteristics method. Analysis starts from the ground surface (line OD, Figure 3 ). The properties of the points located on this boundary can be obtained from Eqs. (7) and (8). Writing Eqs. (4) and (5) in the finite difference form (Appendix A), the unknowns of point $\mathrm{C}$ on the stress characteristics network can be calculated from known points $\mathrm{A}$ and $\mathrm{B}$, where $\mathrm{AC}$ and $\mathrm{BC}$ are the minus and plus characteristics, respectively (Figure 4). Knowing the values of $p, \psi$, 


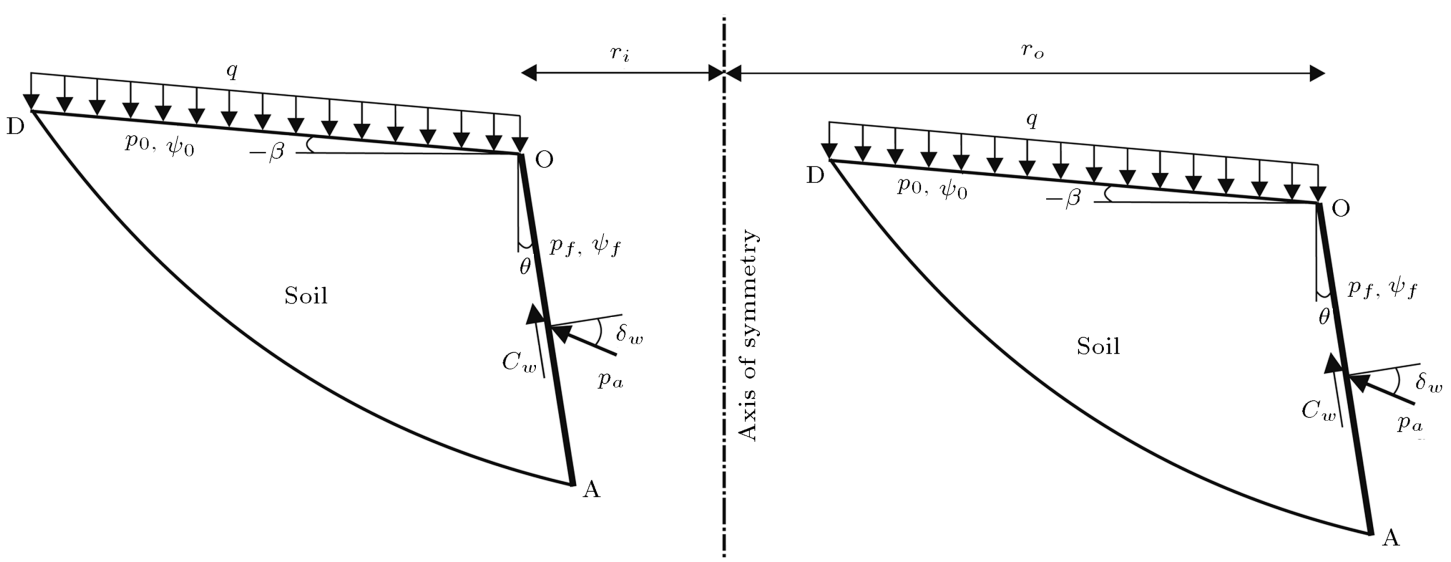

(a)

(b)

Figure 3. Parameters and geometry of the problem for (a) inward and (b) outward retaining walls.

$r$, and $z$ on the boundary OD and using the 3-point strategy, the zone OCD can be generated (Figure 5).

Depending on the values of $\psi_{0}$ and $\psi_{f}$, there exists a network of three types of the stress characteristics (Figure 5). If $\psi_{f}>\psi_{0}$, then the stress characteristics network includes three regions (Figure 5(a)) and if $\psi_{f}=\psi_{0}$, the network would consist of two regions and the region OCB is changed into a line (Figure 5(b)). When $\psi_{f}<\psi_{0}$, region OCB is eliminated and regions ODC and OBA are wrapped together, thus creating a stress discontinuity (Figure 5(c)).

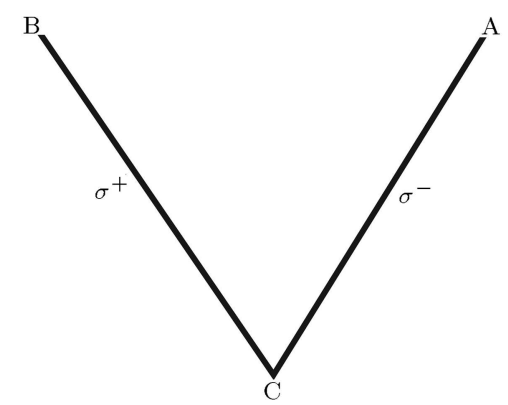

Figure 4. Information at point $\mathrm{C}$ is obtained from points $\mathrm{A}$ and $\mathrm{B}$ along the characteristics.

\section{Type 1: $\psi_{f}>\psi_{0}$}

Because the values of the stress on the left side of point $\mathrm{O}$ are different from those on the right, point $\mathrm{O}$ is singular. In this type, after getting the solution to the region OCD, the singularity point must be solved. The characteristic line close to the singularity point is the positive characteristic. At point $\mathrm{O}, \mathrm{d} r=\mathrm{d} z=0$. As shown in Figure 6, the singularity point is divided into $m$ parts and the value of $\psi$ in each of these parts (part number $i$ ) is obtained as:

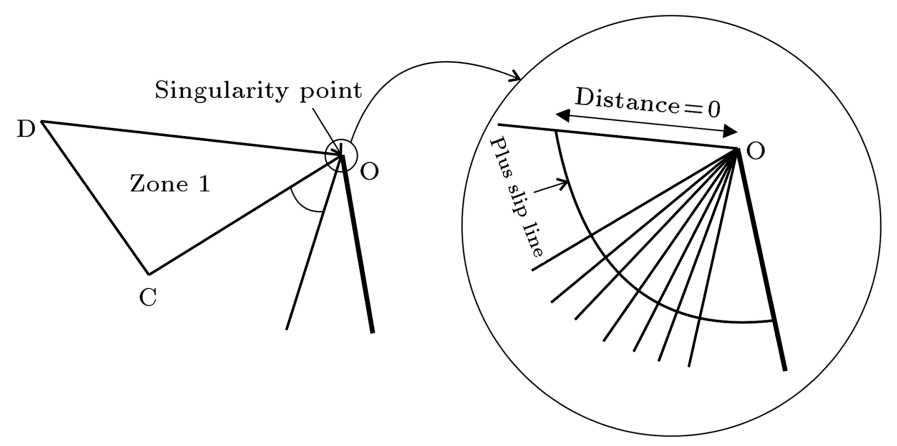

Figure 6. Solving the singularity point.

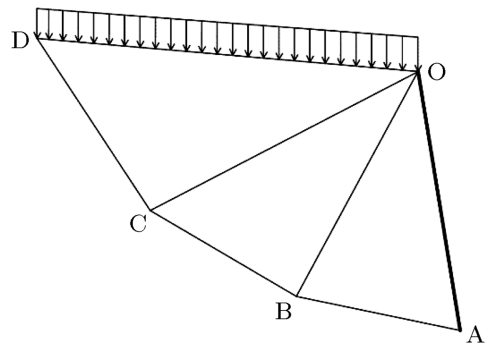

(a) Type 1: $\psi_{f}>\psi_{0}$

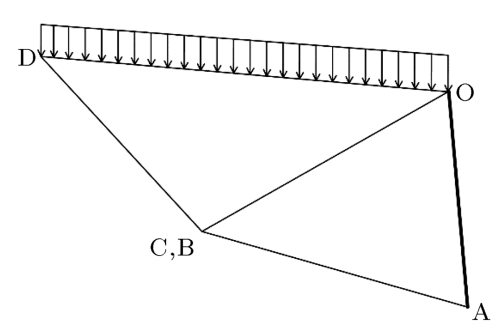

(b) Type 2: $\psi_{f}=\psi_{0}$

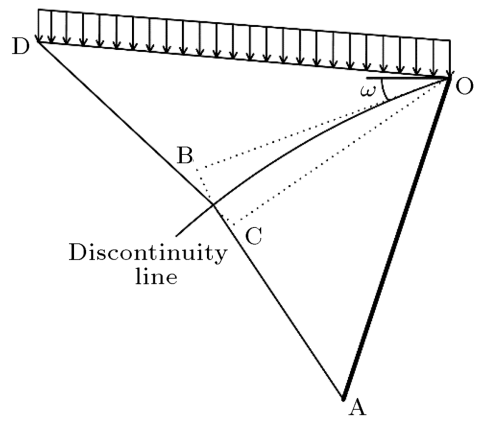

(c) Type 3: $\psi_{f}<\psi_{0}$

Figure 5. The network for different types of the stress characteristics: (a) Type 1, $\psi_{f}>\psi_{0}$, (b) Type 2, $\psi_{f}=\psi_{0}$, and (c) Type $3 \psi_{f}<\psi_{0}$. 


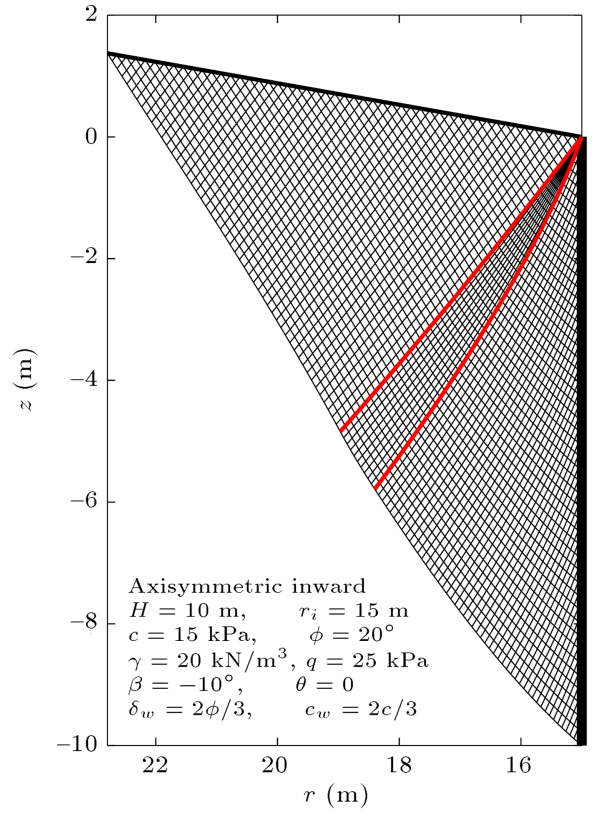

(a)

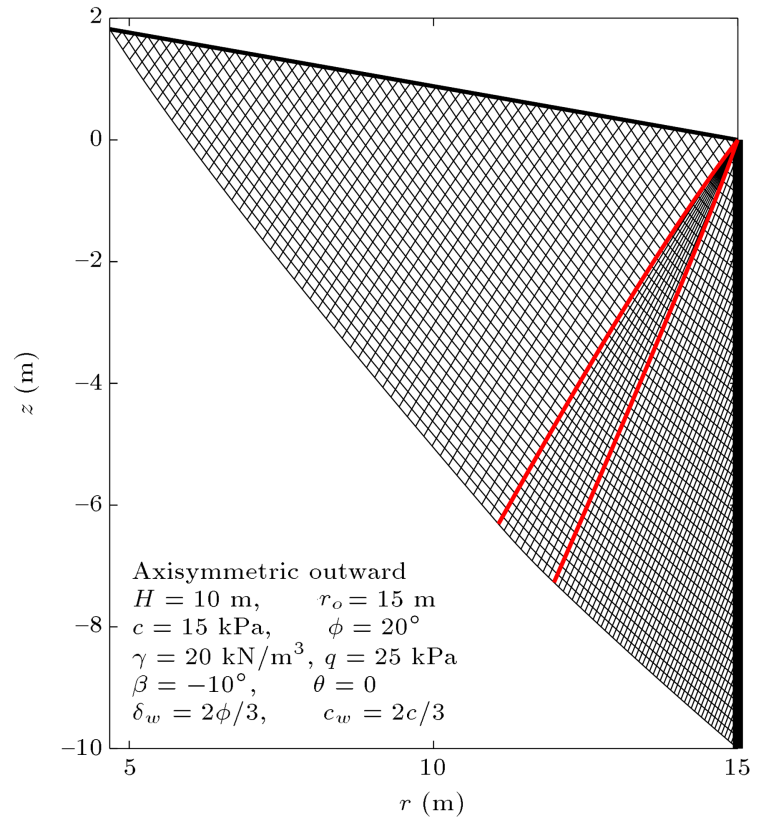

(b)

Figure 7. Typical stress characteristics network for (a) inward and (b) outward retaining wall.

$$
\psi_{i}=\psi_{0}+\frac{i\left(\psi_{f}-\psi_{0}\right)}{m}
$$

Eq. (4) on the singularity point changes into:

$$
\mathrm{d} p+2(p \tan \phi+c) \mathrm{d} \psi=0 .
$$

This equation can be solved to obtain the values of $p_{i}$ as:

$$
\begin{aligned}
& p_{i}=p_{0}-2 c\left(\psi_{i}-\psi_{0}\right) \quad \text { if } \phi=0 \\
& p_{i}=-c \cot \phi+\left(p_{0}+c \cot \phi\right) \exp \left(-2 \tan \phi\left(\psi_{i}-\psi_{0}\right)\right) \\
& \text { if } \phi \neq 0 .
\end{aligned}
$$

Knowing the information at line $\mathrm{OC}$ and point $\mathrm{O}$, the network in the region OCB is calculated. The region $\mathrm{OAB}$ is solved using the information of the line OB and the boundary conditions on the retaining wall.

\section{Type 2: $\psi_{f}=\psi_{0}$}

In this type, the region OCB is changed to a line and the characteristics network consists of two regions. In this type, the solution is obtained in a similar way to that in Type 1. However, in this case, calculation of the zone OCB is not necessary.

\section{Type 3: $\psi_{f}<\psi_{0}$}

In this case, the regions ODC and OBA are wrapped together and a stress discontinuity line exists (Figure 5(c)). To solve this stress discontinuity, the method proposed by Lee and Herington [19] is used with some modifications $[7,34]$.

Figure 7 shows typical stress characteristics networks for the inward and outward retaining walls. The values of the parameters assumed to create these networks are indicated in the figure.

\subsection{Finite element modelling}

To ensure the accuracy of the results obtained by the method of characteristics, the finite element software PLAXIS is used for modeling the active lateral earth pressure in the plane strain and axisymmetric cases. Yang and Liu [35] and Yap et al. [36] have also used the Finite Element Method (FEM) to evaluate the active lateral earth pressure in the plane strain case. Table 1 shows the parameters used in the finite element modeling of the retaining wall. The geometry and boundary conditions of a typical finite element model are shown in Figure 8. Standard fixity and 15 nodes

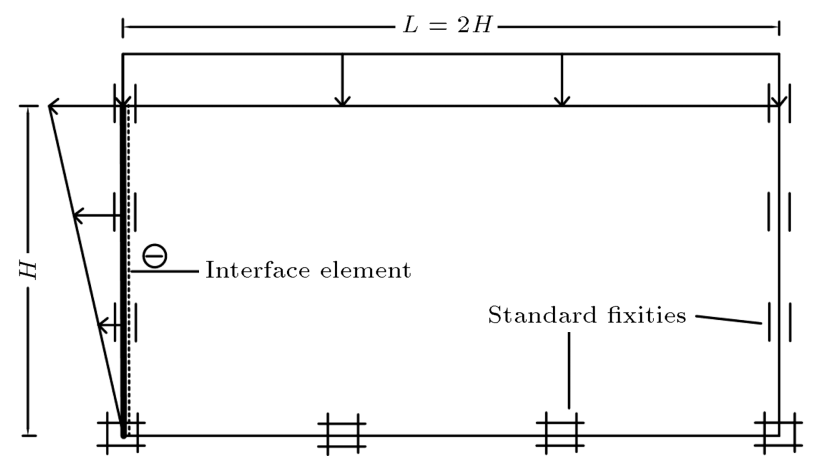

Figure 8. Geometry and boundary conditions of a typical finite element model. 
Table 1. Parameters used for the finite element modeling of the retaining wall.

\begin{tabular}{ccc}
\hline Item & Parameter & Value \\
\hline \multirow{2}{*}{ Soil properties } & Soil unit weight, $\gamma\left(\mathrm{kN} / \mathrm{m}^{3}\right)$ & 20 \\
& Poisson ratio, $v$ & 0.3 \\
& Elastic modulus, $E(\mathrm{kPa})$ & $3.0 \mathrm{E}+4$ \\
& Soil dilation angle $(\mathrm{deg})$ & 30 \\
& & \\
Material properties for retaining wall & Bending stiffness, EI $\left(\mathrm{kN. \textrm {m } ^ { 2 }}\right)$ & $2.5 \mathrm{E}+6$ \\
& Normal stiffness, $E A(\mathrm{kN})$ & $3.0 \mathrm{E}+7$ \\
\hline
\end{tabular}

finite elements with fine mesh are used in the modelling. The rigid retaining wall is modeled as a beam element with properties shown in Table 1. As shown in Figure 8, a prescribed displacement is applied to the retaining wall to rotate the wall outward and force the backfill soil to reach the failure stage to model the active condition. The geometries of the models created for the plane strain or axisymmetric cases are different.

\section{Results and discussions}

A comparison of the results of this study with those of other studies for the plane strain and axisymmetric inward wall is shown in Table 2. The numbers in this table indicate the active lateral earth pressure in $\mathrm{kPa}$ at the bottom of the retaining wall. For the axisymmetric case, the results have been compared with the results of Liu and Wang [27] for different values of 40,100 , and $1000 \mathrm{~m}$ for radius $\left(r_{i}\right)$. As seen, as the radius increases, the lateral earth pressure of the axisymmetric case approaches the plane strain case. As can be observed, the obtained results of the present study are in good agreement with Liu and Wang [27]. Also, the results of this study for $r_{i}=1000$ $\mathrm{m}$ are very close to the results for the plane strain case, Coulomb and Gnanapragasam [5]. The results of Gnanapragasam [5] become much smaller than those of the other studies as the backfill slope increases.

A comparison between the results of the present study with the results of FEM for the lateral earth pressure distribution is shown in Figure 9. Figure 9(a) shows the lateral earth pressure distribution for the axisymmetric inward wall for two values of the wall friction angle $\left(\delta_{w}=\phi / 4,2 \phi / 3\right)$. The horizontal axis presents the lateral earth pressure component normal to the wall $\left(\sigma_{f}\right)$ and the vertical axis shows the vertical coordinates. Similarly, Figure $9(\mathrm{~b})$ and (c) are provided for the axisymmetric outward wall and plane strain cases, respectively. As seen, there are very good agreements between the results of the slip line method and FEM for all cases. In FEM, the maximum lateral earth pressure does not occur at the bottom of the wall. This issue has also been reported by Yap et al. [36].

A comparison between the SCM failure surface and FEM incremental shear strain contour is shown in Figure 10. As clearly seen, the SCM failure surfaces pass through the maximum incremental shear strain zone for both inward and outward walls.

Table 2. A comparison between the active lateral earth pressures at the bottom of the wall $(\mathrm{kPa})$ in this study and other studies for the plane strain and axisymmetric inward cases $\left(c=q=0, \gamma=20 \mathrm{kN} / \mathrm{m}^{3}, \delta_{w}=0, c_{w}=0\right.$, and $\left.H=20 \mathrm{~m}\right)$.

\begin{tabular}{|c|c|c|c|c|c|c|c|c|c|c|}
\hline \multirow[b]{2}{*}{$\begin{array}{c}\phi \\
(\mathrm{deg} .)\end{array}$} & \multirow[b]{2}{*}{$\boldsymbol{\beta}$} & \multicolumn{3}{|c|}{$\begin{array}{c}\text { Inward wall }[27] \\
r_{i}(\mathrm{~m})\end{array}$} & \multicolumn{3}{|c|}{$\begin{array}{c}\text { Inward wall (this study) } \\
r_{i}(\mathrm{~m})\end{array}$} & \multirow[b]{2}{*}{$\begin{array}{l}\text { Plane strain } \\
\text { (this study) }\end{array}$} & \multirow[b]{2}{*}{$\begin{array}{c}\text { Plane strain } \\
\text { (Coulomb) }\end{array}$} & \multirow[b]{2}{*}{$\begin{array}{c}\text { Plane strain } \\
{[5]}\end{array}$} \\
\hline & & 40 & 100 & 1000 & 40 & 100 & 1000 & & & \\
\hline \multirow{3}{*}{10} & 0 & 261.0 & 278.3 & 283.3 & $\begin{array}{l}261.1 \\
\end{array}$ & 272.5 & 280.6 & 281.6 & 281.6 & 281.6 \\
\hline & $-\phi / 3$ & 273.3 & 293.3 & 300.1 & 273.6 & 286.7 & 296.1 & 297.2 & 297.4 & 286.0 \\
\hline & $-2 \phi / 3$ & 290.9 & 315.9 & 326.5 & 289.8 & 303.7 & 313.5 & 314.7 & 320.1 & 305.0 \\
\hline \multirow{3}{*}{20} & 0 & 167.5 & 184.6 & 196.4 & 167.4 & 183.2 & 194.7 & 196.1 & 196.1 & 196.1 \\
\hline & $-\phi / 3$ & 180.0 & 200.5 & 216.0 & 180.0 & 198.9 & 213.1 & 214.8 & 215.0 & 202.9 \\
\hline & $-2 \phi / 3$ & 198.6 & 226.5 & 249.0 & 197.8 & 220.4 & 237.4 & 239.5 & 244.4 & 228.8 \\
\hline \multirow{3}{*}{30} & 0 & 103.4 & 120.2 & 133.1 & 103.5 & 119.6 & 131.8 & 133.3 & 133.3 & 133.3 \\
\hline & $-\phi / 3$ & 112.1 & 132.9 & 149.3 & 111.2 & 132.0 & 147.4 & 149.4 & 149.5 & 139.8 \\
\hline & $-2 \phi / 3$ & 127.1 & 153.3 & 178.3 & 125.3 & 150.2 & 170.1 & 172.7 & 176.4 & 165.7 \\
\hline
\end{tabular}




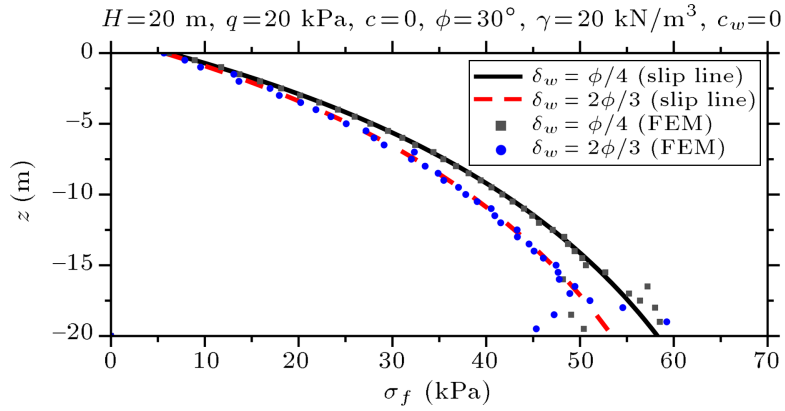

(a) Axisymmetric inward

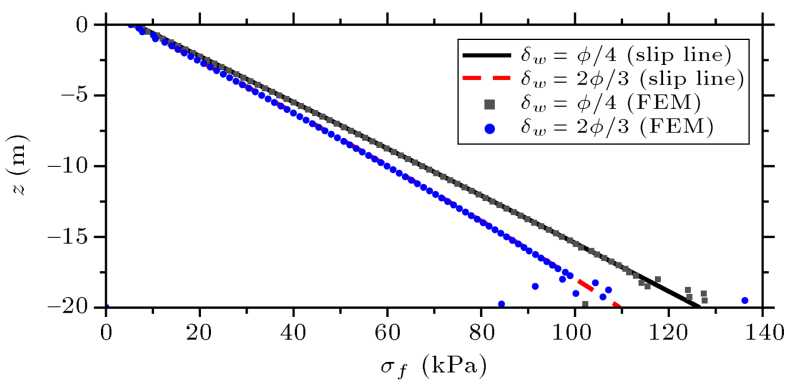

(b) Axisymmetric outward

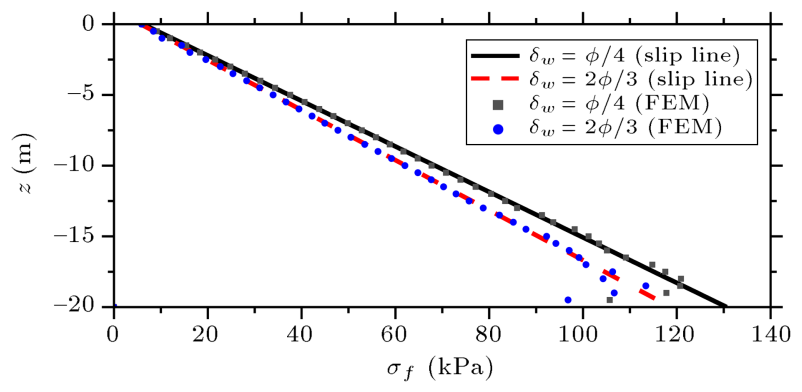

(c) Plane strain

Figure 9. Comparison of the results of the method of characteristics and FEM for the cases of (a) inward, (b) outward, and (c) plane strain.

In the previous works, the effects of the adhesion $\left(c_{w}\right)$ and friction angle $\left(\delta_{w}\right)$ of the soil-wall interface on the lateral earth pressure distribution have not been investigated well. Figures 11 and 12 respectively present the effects of $\delta_{w}$ and $c_{w}$ on the lateral earth pressure distribution. The retaining wall is vertical and the soil surface is horizontal. Each figure shows the obtained results of the axisymmetric and plane strain cases for different values of the soil-wall interface properties. As seen in Figures 11 and 12, in the axisymmetric inward retaining wall, the lateral earth pressure distributions are nonlinear, whereas, in the axisymmetric outward wall and plane strain cases, the earth pressure distributions are almost linear. Furthermore, increasing the soil-wall interface friction angle and adhesion leads to decrease in the active earth pressure. For the results shown in these figures, when $\delta_{w}$ changes from 0 to $\phi$, the lateral earth pressures decrease by about $18.3,29.3$, and $20.18 \%$ for the inward, outward, and plane strain cases, respectively.

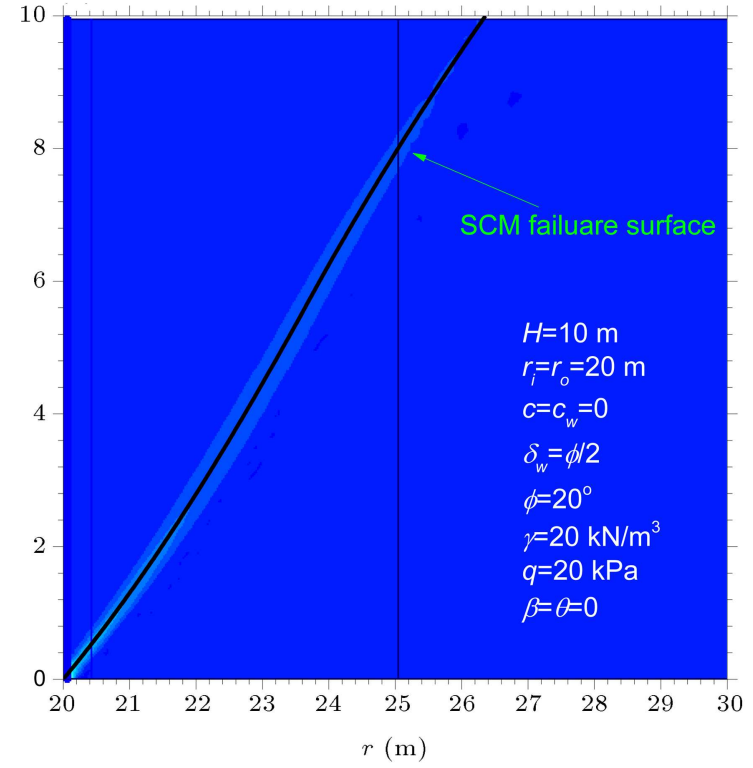

(a) Inward

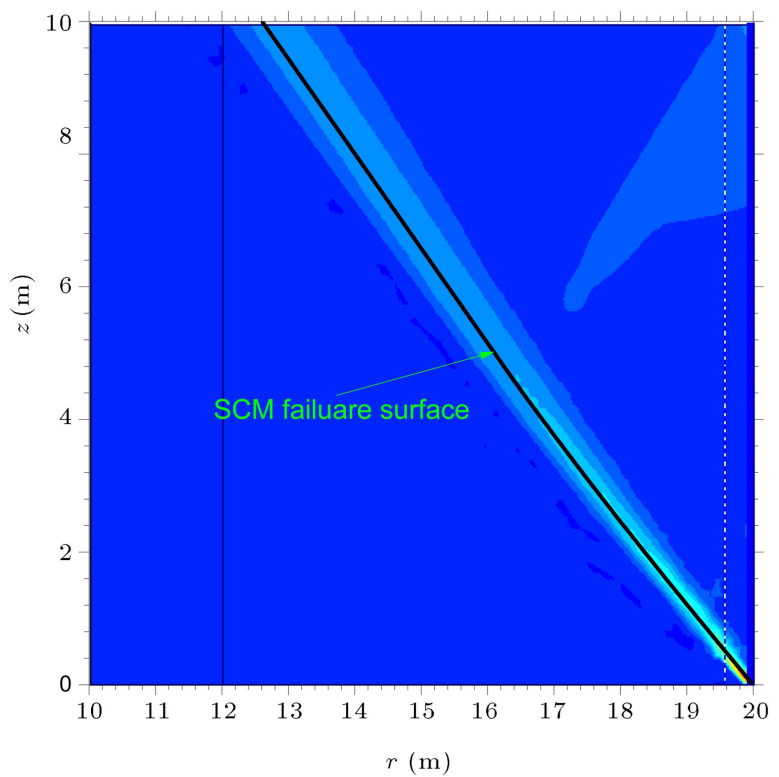

(b) Outward

Figure 10. Comparison between the SCM failure surface and FEM incremental shear strain contour for (a) inward and (b) outward walls.

These decreases, when increasing $c_{w}$ from 0 to $c$, are $29.2,19.2$, and $9.34 \%$, respectively.

Figure 13 has been prepared to investigate the effects of the retaining wall inclination angle $(\theta)$ on the extent of the failure zone. As shown, the failure zone becomes longer and narrower as $\theta$ increases from 0 to 30 degrees. The reduced percentage of the length of the failure zone on the ground surface for $\theta=30^{\circ}$ relative to $\theta=0$ is $44.5,31.8$, and 32.7 for the inward, outward, and plane strain walls, respectively.

Table 3 shows the values of the stress at the bottom of each three types of the retaining walls. As can be seen, with increasing the values of $r_{i}$ and $r_{o}$, 


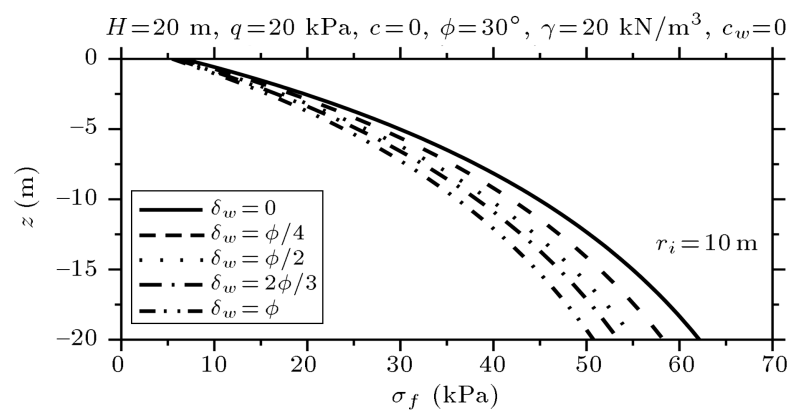

(a) Axisymmetric inward

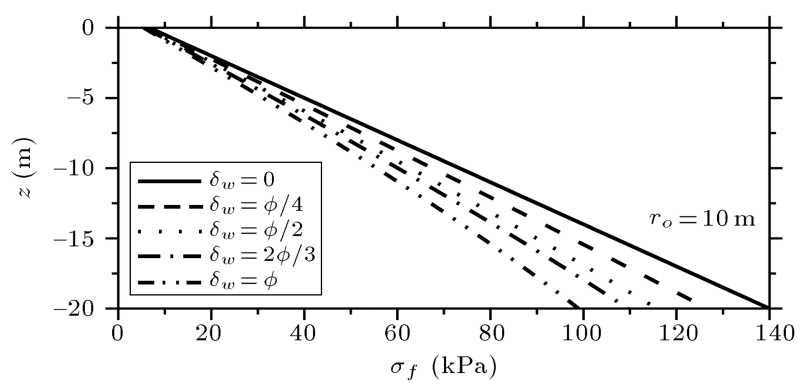

(b) Axisymmetric outward

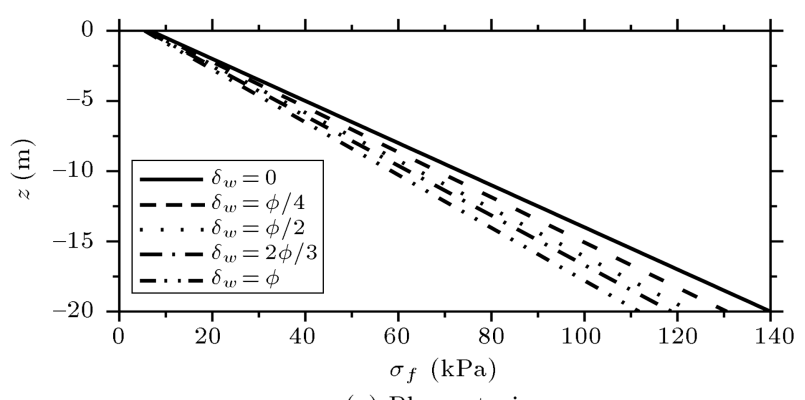

(c) Plane strain

Figure 11. The effect of the wall friction angle on the distribution of the stress for the cases of (a) inward, (b) outward, and (c) plane strain.

the results of the inward and outward walls approach the results of the plane strain case. For the outward wall, increasing $r_{o}$ has a lower effect on the lateral earth pressure. This effect becomes even lower as the friction angle increases. Overall, the differences between the results of the plain strain and the outward and inward walls are about $5 \%$ and $15 \%$, respectively.

The results of the previously presented figures and tables indicate that the lateral earth pressures obtained for the axisymmetric outward wall are very close to the plane strain results. Therefore, in practice, the active lateral earth pressure of the axisymmetric outward retaining wall can be found from the plane strain analysis with small error.

Soil cohesion causes the value of the active lateral earth pressure to be negative from the ground surface to some depth. The plastic critical depth is the depth where computed active lateral earth pressure is negative. Many researchers believe that the soil does not have the ability to withstand tension and the value

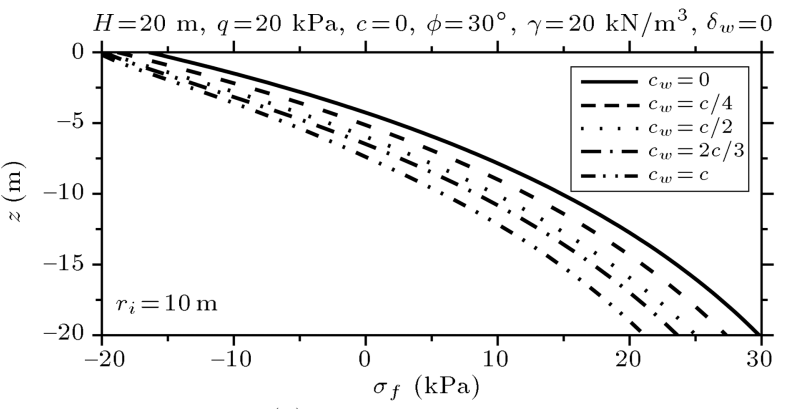

(a) Axisymmetric inward

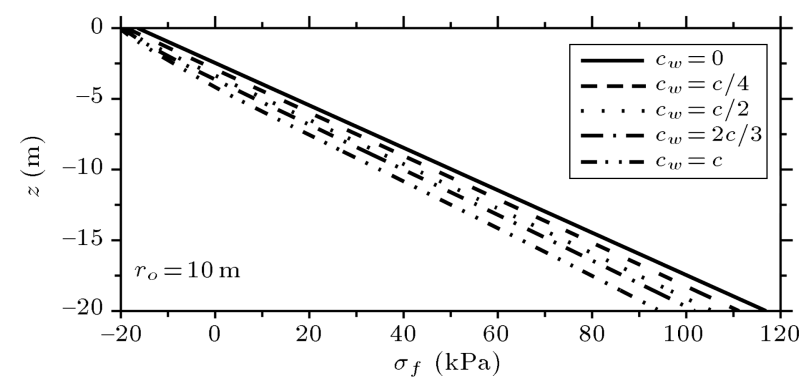

(b) Axisymmetric outward

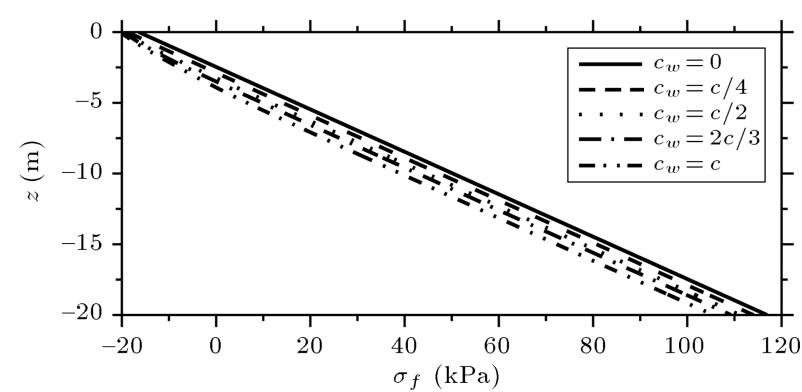

(c) Plane strain

Figure 12. The effect of the wall adhesion on the distribution of the stress for the cases of (a) inward, (b) outward, and (c) plane strain.

of the active lateral earth pressure is zero from the ground surface to the plastic critical depth [22,37-41].

In this analysis, to calculate this depth, an equivalent surcharge approach is used (Figure 14). Using this approach, Peng and Chen [21] and Keshavarz [22] introduced closed-form solutions to compute the plastic critical depth for the plane strain case. Because in the axisymmetric case the lateral earth pressure is nonlinear, the closed-form solution of Peng and Chen [21] cannot be used in this case. Therefore, a trial and error procedure is employed in this paper.

To compute the plastic critical depth, $z_{0}$, first, the characteristics network is obtained and the initial negative lateral earth pressure depth is found. Then, the equivalent surcharge is computed as:

$$
\tilde{q}=q+\gamma z_{0}
$$

In the second try, $\tilde{q}$ is used instead of $q$ and the problem is solved; afterwards, the new $z_{0}$ and then new $\tilde{q}$ are obtained. This trial and error process is repeated until the computed lateral earth pressure on the ground 


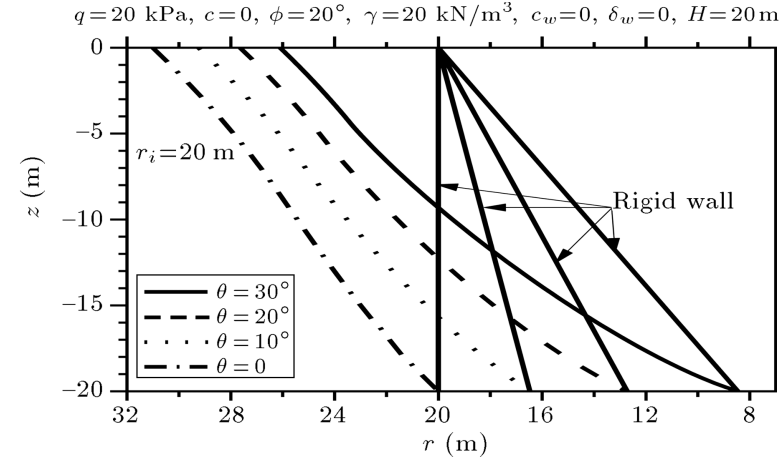

(a) Axisymmetric inward

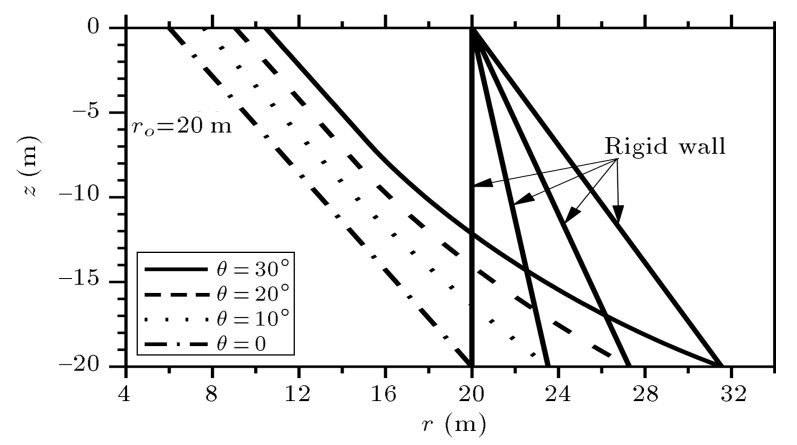

(b) Axisymmetric outward

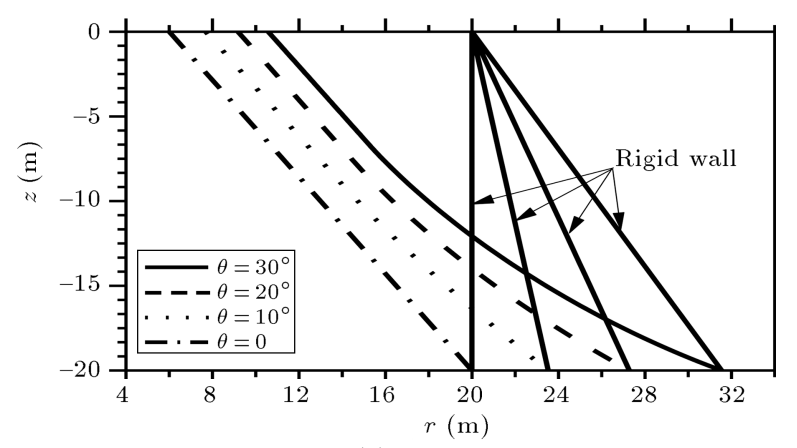

(c) Plane strain

Figure 13. The effect of the wall inclination angle on the failure region for the cases of (a) inward, (b) outward, and (c) plane strain.

surface is zero. It must be noted that in the trial and error process, the value of the lateral earth pressure on the ground surface may be greater than zero. In this case, $z_{0}$ must be changed in small steps until the lateral pressure on the ground surface becomes zero.

Finally, the value of the plastic critical depth can be found as:

$$
z_{0}=\frac{\tilde{q}-q}{\gamma} \geq 0
$$

Table 4 shows a comparison between the computed values of $z_{0}$ in this study for the plane strain case and the results of the previous works for different values of $\phi, c$, and $q$. The results of this paper for $z_{0}$ are almost same as the results of Peng and Chen [21].

After investigations conducted on the plastic critical depth in the axisymmetric and plane strain cases,

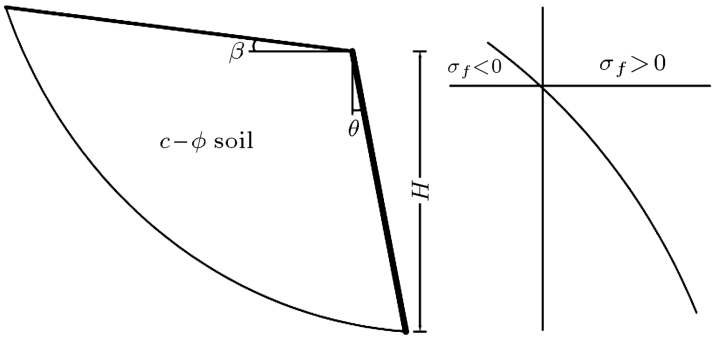

(a)

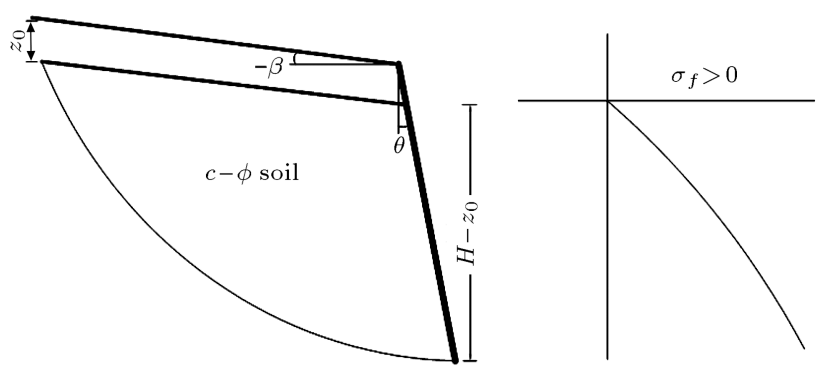

(b)

Figure 14. The models of the retaining wall: (a) Without considering the plastic critical depth, and (b) with considering the plastic critical depth.

it can be concluded that the height of the retaining wall and the wall case (axisymmetric or plane strain) have very small effects on this depth. Therefore, the plastic critical depth in the axisymmetric case can be found from the plane strain analysis. For the stress characteristics method, a closed form solution proposed by Peng and Chen [21] or Keshavarz [22] can be used.

A comparison between the results of the SCM and FEM for the lateral earth pressure distribution considering the plastic critical depth has been shown in Figure 15. As shown, the maximum difference is observed in the inward wall (Figure 15(a)) and FEM predicts larger values for the plastic critical depth. Also, in FEM, some irregularities occur on the lateral earth pressure at the bottom of the wall.

In order to evaluate the effects of the plastic critical depth on the lateral earth pressure, two dimensionless parameters are employed:

$$
\begin{aligned}
p_{a}^{*} & =\frac{p_{a}}{\gamma H^{2}}, \\
c^{*} & =\frac{c}{\gamma H},
\end{aligned}
$$

where $p_{a}$ is the active lateral earth force, which is the resultant force of the normal and shear stresses along the retaining wall boundary. Figure 16 shows the values of $p_{a}^{*}$ for inward wall as a function of $r_{i} / H$. Results have been presented with and without considering the plastic critical depth for different values of $c^{*}$ and $\phi$. As seen, considering the plastic critical depth leads to increase in $p_{a}^{*}$. This effect is greater for larger values 
Table 3. The values of the stress in $\mathrm{kPa}$ at the bottom of all the three types of the walls for different values of parameters $\left(c=20 \mathrm{kPa}, q=20 \mathrm{kPa}, \gamma=20 \mathrm{kN} / \mathrm{m}^{3}, \delta_{w}=\phi / 3, c_{w}=c / 2, H=10 \mathrm{~m}\right.$, and $\left.\theta=0\right)$.

\begin{tabular}{|c|c|c|c|c|c|c|c|c|c|c|}
\hline \multirow[b]{2}{*}{$\phi$ (deg.) } & \multirow[b]{2}{*}{$\beta$ (deg.) } & \multicolumn{4}{|c|}{ Inward wall $r_{i}(\mathrm{~m})$} & \multicolumn{4}{|c|}{ Outward wall $r_{\circ}(\mathrm{m})$} & \multirow[b]{2}{*}{ Plane strain } \\
\hline & & 15 & 50 & 100 & 1000 & 15 & 50 & 100 & 1000 & \\
\hline \multirow{3}{*}{10} & 0 & 81.8 & 99.1 & 103.9 & 108.8 & 105.9 & 108.4 & 108.9 & 109.2 & 109.3 \\
\hline & -5 & 88.1 & 108.1 & 113.8 & 119.8 & 114.9 & 119.1 & 119.9 & 120.5 & 120.6 \\
\hline & -10 & 96.4 & 120.7 & 128.3 & 136.7 & 126.2 & 134.9 & 136.4 & 137.6 & 137.8 \\
\hline \multirow{3}{*}{20} & 0 & 40.7 & 58.1 & 63.0 & 67.9 & 66.3 & 67.9 & 68.2 & 68.5 & 68.5 \\
\hline & -5 & 43.2 & 62.2 & 67.7 & 73.4 & 71.0 & 73.3 & 73.7 & 74.0 & 74.1 \\
\hline & -10 & 46.0 & 67.2 & 73.6 & 80.3 & 76.8 & 80.0 & 80.6 & 81.1 & 81.1 \\
\hline \multirow{3}{*}{30} & 0 & 16.4 & 31.6 & 36.1 & 40.6 & 39.7 & 40.8 & 40.9 & 41.1 & 41.1 \\
\hline & -5 & 17.3 & 33.4 & 38.3 & 43.3 & 42.2 & 43.4 & 43.6 & 43.8 & 43.9 \\
\hline & -10 & 18.2 & 35.5 & 40.8 & 46.4 & 45.1 & 46.6 & 46.8 & 47.1 & 47.1 \\
\hline \multirow{3}{*}{40} & 0 & 2.5 & 14.5 & 18.2 & 22.1 & 21.8 & 22.3 & 22.5 & 22.6 & 22.6 \\
\hline & -5 & 2.7 & 15.2 & 19.1 & 23.3 & 22.9 & 23.6 & 23.7 & 23.8 & 23.8 \\
\hline & -10 & 3.0 & 16.0 & 20.2 & 24.7 & 24.3 & 25.0 & 25.4 & 25.5 & 25.5 \\
\hline
\end{tabular}

Table 4. A comparison between the values of the plastic critical depth $\left(z_{0}\right)$ for the plane strain case in this study and the results of other researchers $\left(\gamma=20 \mathrm{kN} / \mathrm{m}^{3}, c_{w}=2 c / 3, \delta_{w}=2 \phi / 3, \beta=-10^{\circ}\right.$, and $\left.\theta=10^{\circ}\right)$.

\begin{tabular}{|c|c|c|c|c|c|c|c|c|}
\hline \multirow[b]{2}{*}{$\phi(\mathrm{deg})$} & \multirow[b]{2}{*}{$c(\mathrm{kPa})$} & \multirow[b]{2}{*}{$q(\mathrm{kPa})$} & \multicolumn{6}{|c|}{$z_{0}(\mathrm{~m})$} \\
\hline & & & $\begin{array}{c}\text { Nian and } \\
\text { Han }[40]\end{array}$ & $\begin{array}{c}\text { Lin } \\
\text { et al. [38] }\end{array}$ & $\begin{array}{c}\text { Iskander } \\
\text { et al. }[37]\end{array}$ & $\begin{array}{c}\text { Peng } \\
{[41]}\end{array}$ & $\begin{array}{l}\text { Peng and } \\
\text { Chen [21] }\end{array}$ & $\begin{array}{l}\text { This } \\
\text { study }\end{array}$ \\
\hline \multirow{4}{*}{10} & \multirow{2}{*}{10} & 0 & 1.1918 & 1.5426 & 1.1751 & 1.8004 & 1.6739 & 1.6740 \\
\hline & & 10 & 0.6917 & 1.0552 & 0.6751 & 1.3004 & 1.1739 & 1.1740 \\
\hline & \multirow{2}{*}{20} & 0 & 2.3835 & 2.5240 & 2.3543 & 3.6007 & 3.3479 & 3.3479 \\
\hline & & 10 & 1.8835 & 2.0397 & 1.8543 & 3.1007 & 2.8479 & 2.8479 \\
\hline \multirow{4}{*}{20} & \multirow[t]{2}{*}{10} & 0 & 1.4281 & 1.3106 & 1.4229 & 2.3059 & 2.1229 & 2.1229 \\
\hline & & 10 & 0.9281 & 0.8123 & 0.9229 & 2.8059 & 1.6229 & 1.6229 \\
\hline & \multirow{2}{*}{20} & 0 & 2.8563 & 2.5122 & 2.8715 & 4.6119 & 4.2452 & 4.2451 \\
\hline & & 10 & 2.3563 & 2.0165 & 2.3715 & 4.1119 & 3.7452 & 3.7451 \\
\hline \multirow{4}{*}{30} & \multirow{2}{*}{10} & 0 & 1.7321 & 1.4588 & 1.7468 & 3.0318 & 2.7514 & 2.798 \\
\hline & & 10 & 1.2321 & 0.9597 & 1.2468 & 2.5318 & 2.2514 & 2.2521 \\
\hline & \multirow{2}{*}{20} & 0 & 3.4641 & 2.8531 & 3.4937 & 6.0635 & 5.5029 & 5.5032 \\
\hline & & 10 & 2.9641 & 2.3558 & 2.9937 & 2.3558 & 5.0029 & 5.0036 \\
\hline \multirow{4}{*}{40} & \multirow{2}{*}{10} & 0 & 2.1445 & 1.7340 & 2.3588 & 4.1766 & 3.7059 & 3.7068 \\
\hline & & 10 & 1.6445 & 1.2347 & 1.8588 & 3.6766 & 3.2059 & 3.2039 \\
\hline & \multirow{2}{*}{20} & 0 & 4.2890 & 3.4184 & 4.6856 & 8.3532 & 7.4118 & 7.4117 \\
\hline & & 10 & 3.7890 & 2.9205 & 4.1858 & 7.8532 & 6.9118 & 6.9128 \\
\hline
\end{tabular}




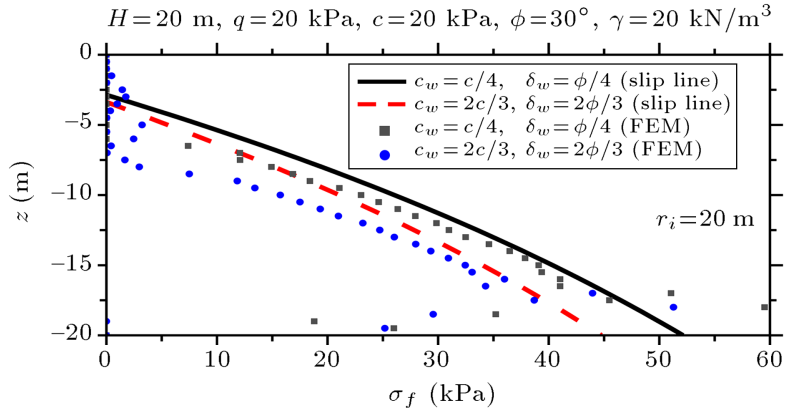

(a) Axisymmetric inward

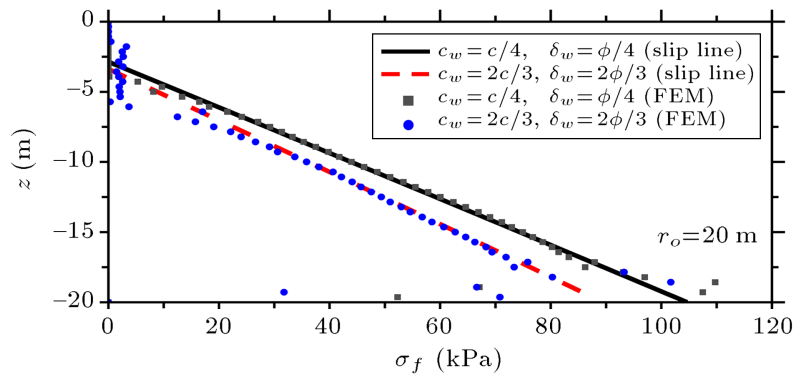

(b) Axisymmetric outward

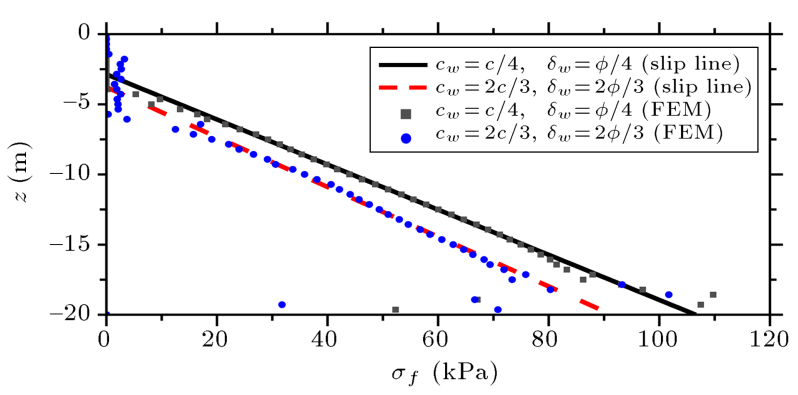

(c) Plane strain

Figure 15. Comparison between the results of the method of characteristics with FEM considering the plastic critical depth for (a) inward, (b) outward, and (c) plane strain retaining walls.

of $c^{*}$. When the plastic critical depth is considered in the solution, $p_{a}^{*}$ is always positive. But, without considering $z_{0}$, in some cases, especially for large values of $c^{*}$ (Figure 16(c)), $p_{a}^{*}$ can be negative.

Table 5 is prepared to evaluate $p_{a} *$ in the outward case of the retaining wall with and without considering the plastic critical depth. As seen, in this case, $p_{a}^{*}$ is

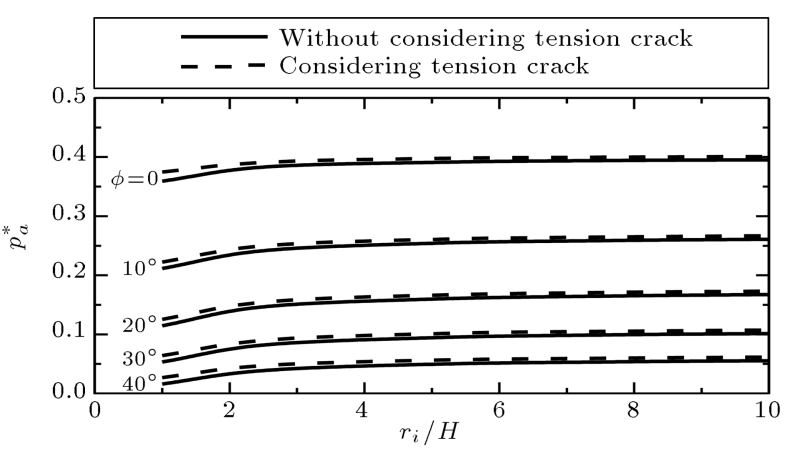

(a) $c^{*}=0.05$

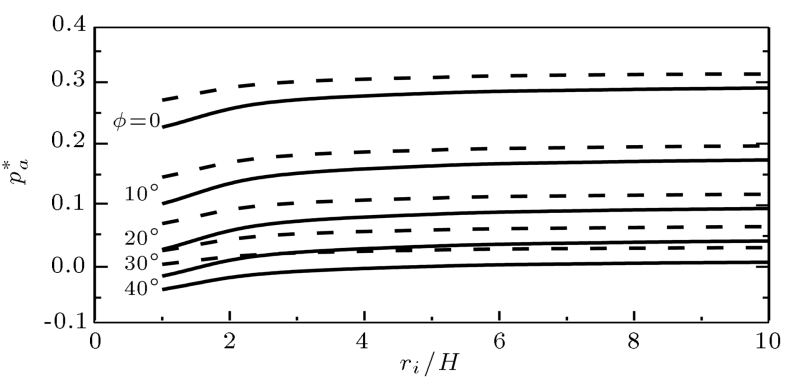

(b) $c^{*}=0.1$

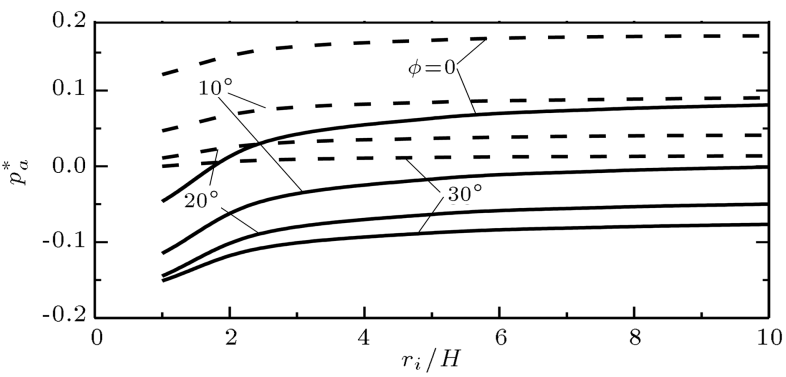

(c) $c^{*}=0.2$

Figure 16. Variations of $p_{a}^{*}$ in the inward retaining wall with and without considering the plastic critical depth for (a) $c^{*}=0.05$, (b) $c^{*}=0.1$, and (c) $c^{*}=0.2(q=0$, $\gamma=20 \mathrm{kN} / \mathrm{m}^{3}, \delta_{w}=0, c_{w}=0$, and $\left.\theta=\beta=0\right)$.

also greater when the plastic critical depth is taken into account. Therefore, it is not conservative to neglect the effect of the plastic critical depth.

\section{Conclusions}

This study evaluated the axisymmetric active lateral

Table 5. Variations of $p_{a}^{*}$ in the outward retaining wall with and without considering the plastic critical depth $z_{0}(q=0$, $\gamma=20 \mathrm{kN} / \mathrm{m}^{3}, \delta_{w}=0, c_{w}=0$, and $\left.\theta=\beta=0\right)$.

\begin{tabular}{ccccccc}
\hline $\boldsymbol{\phi}$ (deg.) & \multicolumn{2}{c}{ Without considering the effect of $\boldsymbol{z}_{\mathbf{0}}$} & \multicolumn{3}{c}{ With considering the effect of $\boldsymbol{z}_{\mathbf{0}}$} \\
\cline { 2 - 7 } & $\boldsymbol{c}^{*}=\mathbf{0 . 0 5}$ & $\boldsymbol{c}^{*}=\mathbf{0 . 1}$ & $\boldsymbol{c}^{*}=\mathbf{0 . 2}$ & $\boldsymbol{c}^{*}=\mathbf{0 . 0 5}$ & $\boldsymbol{c}^{*}=\mathbf{0 . 1}$ & $\boldsymbol{c}^{*}=\mathbf{0 . 2}$ \\
\hline 0 & 0 & 0.3 & 0.1 & 0.4047 & 0.3195 & 0.1792 \\
10 & 10 & 0.1842 & 0.0164 & 0.2729 & 0.2038 & 0.0958 \\
20 & 20 & 0.1051 & -0.0349 & 0.1799 & 0.1248 & 0.0447 \\
30 & 30 & 0.0512 & -0.0643 & 0.1138 & 0.0710 & 0.0155 \\
40 & 40 & 0.0155 & -0.0778 & 0.0670 & 0.0353 & 0.0021 \\
\hline
\end{tabular}


earth pressure of retaining wall using the method of stress characteristics. Two types of the retaining walls in the axisymmetric case were considered. In the inward case, the problem was similar to the circular excavation, but in the outward case, the axis of symmetry lay in the soil media. It is conservative to use the results of the plane strain case for the axisymmetric walls.

The results showed that the values of the lateral earth pressure for the outward and plain strain cases were very close to each other. To verify the results of the stress characteristics method, finite element modelling was used. Furthermore, the results were compared with those of the previous works. Comparisons indicated the accuracy of the proposed method.

The effects of the soil and wall parameters, including the soil-wall interface adhesion and friction angle, were evaluated. Also, the effect of the plastic critical or tension crack depth on the lateral earth pressure was considered. The obtained results showed that the plastic critical depth could be calculated by the methods proposed for the plane strain case. When the plastic critical depth is considered in the analysis, the lateral earth force will be increased. Therefore, it is better to take into account the plastic critical depth.

\section{References}

1. Coulomb, C.A., Tests on an Application of the Rules of Maximum and Minimum to Some Static Problems Related to Architecture, Royal Academy of Sciences (in French) (1776).

2. Rankine, W.M. "On the stability of loose earth", Philosophical Transactions of the Royal Society of London, 147, pp. 9-27 (1857).

3. Terzaghi, K., Theoretical Soil Mechanics, Wiley (1943).

4. Mazindrani, Z. and Ganjali, M. "Lateral earth pressure problem of cohesive backfill with inclined surface", J. Geotech. Geoenviron. Eng., 123(2), pp. 110-112 (1997).

5. Gnanapragasam, N. "Active earth pressure in cohesive soils with an inclined ground surface", Can. Geotech. J., 37(1), pp. 171-177 (2000).

6. Fang, Y.S., Chen, J.M. and Chen, C.Y. "Earth pressures with sloping backfill", J. Geotech. Geoenviron. Eng., 123(3), pp. 250-259 (1997).

7. Keshavarz, A. and Pooresmaeil, Z. "Evaluation of the static and seismic active lateral earth pressure for c-f soils by the ZEL method", Sci. Iran, 23(1), pp. 142154 (2016).

8. Lancellotta, R. "Analytical solution of passive earth pressure", Géotechnique, 52(8), pp. 617-619 (2002).

9. Sokolovskii, V.V., Statics of Soil Media., Butterworths Scientific Publications (1960).
10. Sokolovskii, V.V., Statics of Granular Media., Pergamon (1965).

11. Gao, F.P., Wang, N. and Zhao, B. "Ultimate bearing capacity of a pipeline on clayey soils: Slip-line field solution and FEM simulation", Ocean Eng., 73, pp. 159-167 (2013).

12. Jahanandish, M. and Keshavarz, A. "Seismic bearing capacity of foundations on reinforced soil slopes", Geotext. Geomembr., 23(1), pp. 1-25 (2005).

13. Keshavarz, A., Fazeli, A. and Sedeghi, S. "Seismic bearing capacity of strip footings on rock masses using the Hoek-Brown failure criterion", Journal of Rock Mechanics and Geotechnical Engineering, 8(2), pp. 170-177 (2016).

14. Keshavarz, A., Jahanandish, M. and Ghahramani, A. "Seismic bearing capacity analysis of reinforced soils by the method of stress characteristics", IJST T. Civ. Eng., 35(C2), pp. 185-197 (2011).

15. Veiskarami, M., Eslami, A. and Kumar, J. "Endbearing capacity of driven piles in sand using the stress characteristics method: analysis and implementation", Can. Geotech. J., 48(10), pp. 1570-1586 (2011).

16. Veiskarami, M., Kumar, J. and Valikhah, F. "Effect of the flow rule on the bearing capacity of strip foundations on sand by the upper-bound limit analysis and slip lines", Int. J. Geomech., 14(3), p. 04014008 (2014).

17. Cheng, Y. "Seismic lateral earth pressure coefficients for c- $\phi$ soils by slip line method", Comput. Geotech., 30(8), pp. 661-670 (2003).

18. Kumar, J. and Chitikela, S. "Seismic passive earth pressure coefficients using the method of characteristics", Can. Geotech. J., 39(2), pp. 463-471 (2002).

19. Lee, I. and Herington, J. "A theoretical study of the pressures acting on a rigid wall by a sloping earth or rock fill", Geotechnique, 22(1), pp. 1-26 (1972).

20. Vo, T. and Russell, A.R. "Slip line theory applied to a retaining wall-unsaturated soil interaction problem", Comput. Geotech., 55, pp. 416-428 (2014).

21. Peng, M.X. and Chen, J. "Slip-line solution to active earth pressure on retaining walls", Geotechnique, 63(12), pp. 1008-1019 (2013).

22. Keshavarz, A. "Evaluation of the plastic critical depth in seismic active lateral earth pressure problems using the stress characteristics method", Acta Geotech. Slov., 13(1), pp. 19-27 (2016).

23. Berezantzev, V. "Earth pressure on the cylindrical retaining walls", in Conference on Earth Pressure Problems, Brussels. pp. 21-27 (1958). 
24. Cheng, Y., Au, S., Hu, Y. and Wei, W. "Active pressure for circular cut with berezantzev's and prater's theories, numerical modeling and field measurements", Soils Found., 48(5), pp. 621-631 (2008).

25. Liu, F., Wang, J. and Zhang, L. "Axi-symmetric active earth pressure for layered backfills obtained by the slip line method", Journal of Shanghai Jiaotong University (Science), 13, pp. 579-584 (2008).

26. Cheng, Y., Hu, Y. and Wei, W. "General axisymmetric active earth pressure by method of characteristicstheory and numerical formulation", Int. J. Geomech., 7(1), pp. 1-15 (2007).

27. Liu, F. and Wang, J. "A generalized slip line solution to the active earth pressure on circular retaining walls", Comput. Geotech., 35(2), pp. 155-164 (2008).

28. Liu, F., Wang, J. and Zhang, L. "Axi-symmetric active earth pressure obtained by the slip line method with a general tangential stress coefficient", Comput. Geotech., 36(1), pp. 352-358 (2009).

29. Liu, F. "Lateral earth pressures acting on circular retaining walls", Int. J. Geomech., 14(3), p. 04014002 (2014).

30. Jahanandish, M. "Development of a zero extension line method for axially symmetric problems in soil mechanics", Sci. Iran, 10(2), pp. 203-210 (2003).

31. Haar, A. and Karman, T.V. "On the theory of stress states in plastic and sand-like media", News from the Society of Sciences to Göttingen, Mathematicalphysical Class, pp. 204-218 (in German) (1909).

32. Tobar, T. and Meguid, M.A. "Experimental study of the earth pressure distribution on cylindrical shafts", J. Geotech. Geoenviron. Eng., 137(11), pp. 1121-1125 (2011).

33. Tran, V.D., Meguid, M.A. and Chouinard, L.E. "Discrete element and experimental investigations of the earth pressure distribution on cylindrical shafts", Int. J. Geomech., 14(1), pp. 80-91 (2012).

34. Keshavarz, A. and Pooresmaeil, Z. "Static and seismic active lateral earth pressure coefficients for c-f soils", Geomech. Eng., 10(5), pp. 657-676 (2016).

35. Yang, K.H. and Liu, C.N. "Finite element analysis of earth pressures for narrow retaining walls", Journal of GeoEngineering, 2(2), pp. 43-52 (2007).

36. Yap, S., Salman, F. and Shirazi, S. "Comparative study of different theories on active earth pressure", J. Cent. South Univ., 19(10), pp. 2933-2939 (2012).

37. Iskander, M., Chen, Z., Omidvar, M., Guzman, I. and Elsherif, O. "Active static and seismic earth pressure for c- $\phi$ soils", Soils Found., 53(5), pp. 639-652 (2013).
38. Lin, Y.L., Leng, W.M., Yang, G.L., Zhao, L.H., Li, L. and Yang, J.S. "Seismic active earth pressure of cohesive-frictional soil on retaining wall based on a slice analysis method", Soil Dyn. Earthquake Eng., 70, pp. 133-147 (2015).

39. Ma, S.J., Wang, K.H. and Wu, W.B. "Pseudo-dynamic active earth pressure behind retaining wall for cohesive soil backfill", J. Cent. South Univ., 19, pp. 3298-3304 (2012).

40. Nian, T. and Han, J. "Analytical solution for rankine's seismic active earth pressure in c- $\phi$ soil with infinite slope", J. Geotech. Geoenviron. Eng., 139(9), pp. 1611-1616 (2012).

41. Peng, M.X. "Coulomb solution to seismic active earth pressure on retaining walls", Chinese Journal of Rock Mechanics and Engineering, 31(3), pp. 640-648 (2012).

\section{Appendix}

The values of $r_{C}$ and $z_{C}$ are determined by writing the finite difference form of Eqs. (4) and (5) as follows:

$$
\text { for } \begin{aligned}
\sigma^{+}: \frac{z_{C}-z_{B}}{r_{C}-r_{B}} & =0.5\left(\tan \left(\psi_{C}+\zeta\right)\right. \\
& \left.+\tan \left(\psi_{B}+\zeta\right)\right)=t_{1} \\
\text { for } \quad \sigma^{-}: \frac{z_{C}-z_{A}}{r_{C}-r_{A}}= & 0.5\left(\tan \left(\psi_{C}-\zeta\right)\right. \\
& \left.+\tan \left(\psi_{B}-\zeta\right)\right)=t_{2} .
\end{aligned}
$$

Then, the values of $r_{C}$ and $z_{C}$ can be determined by:

$$
\begin{aligned}
& r_{C}=\frac{z_{A}-z_{B}-r_{A} t_{2}+r_{B} t_{1}}{t_{1}-t_{2}} \\
& z_{C}=\left(r_{C}-r_{B}\right) t_{1}+z_{B} .
\end{aligned}
$$

The values of $p_{C}$ and $\psi_{C}$ can be determined by formulating Eqs. (4) and (5) in the finite difference form as follows:

$$
\begin{aligned}
& \text { for } \sigma^{+}:\left(p_{C}-p_{B}\right)+B_{1}\left(\psi_{C}-\psi_{B}\right)=C_{1}+D_{1}, \\
& \text { for } \sigma^{-}:\left(p_{C}-p_{A}\right)+B_{2}\left(\psi_{C}-\psi_{A}\right)=C_{2}+D_{2},
\end{aligned}
$$

where:

$$
\begin{aligned}
& B_{1}=\left(p_{C}+p_{B}\right) \tan \phi+2 c, \\
& B_{2}=-\left(p_{C}+p_{A}\right) \tan \phi-2 c, \\
& C_{1}=0.5\left(f_{r C}+f_{r B}\right)\left[\left(r_{C}-r_{B}\right)-\left(z_{C}-z_{B}\right) \tan \phi\right], \\
& C_{2}=0.5\left(f_{r C}+f_{r A}\right)\left[\left(r_{C}-r_{A}\right)-\left(z_{C}-z_{A}\right) \tan \phi\right], \\
& D_{1}=0.5\left(f_{z C}+f_{z B}\right)\left[\left(r_{C}-r_{B}\right) \tan \phi+\left(z_{C}-z_{B}\right)\right], \\
& D_{2}=0.5\left(f_{z C}+f_{z A}\right)\left[-\left(r_{C}-r_{A}\right) \tan \phi+\left(z_{C}-z_{A}\right)\right] .
\end{aligned}
$$


By solving Eq. (A.4), the values of $p_{C}$ and $\psi_{C}$ can be obtained as:

$$
\begin{aligned}
& \psi_{C}=A_{1} / A_{2}, \\
& p_{C}=p_{B}+C_{1}+D_{1}-B_{1}\left(\psi_{C}-\psi_{B}\right),
\end{aligned}
$$

where:

$$
\begin{aligned}
& A_{1}=p_{B}-p_{A}+C_{1}+D_{1}+B_{1} \psi_{B}-B_{2} \psi_{A}-C_{2}-D_{2}, \\
& A_{2}=B_{1}-B_{2} .
\end{aligned}
$$

\section{Biographies}

Amin Keshavarz is currently an Assistant Professor of Civil Engineering in the School of Engineering at
Persian Gulf University, Iran. He received his BSc degree in Civil Engineering from Persian Gulf University in 1997. He also received his MSc and PhD degrees in Civil Engineering (Soil Mechanics and Foundations) from Shiraz University, Iran, in 2000 and 2007, respectively. His research interests are stress characteristics and ZEL methods, soil dynamics and geotechnical earthquake engineering, and stability analysis of reinforced and unreinforced soil slopes and retaining walls.

Mohsen Ebrahimi received his BSc degree in Civil Engineering in 2013. He also obtained his MSc degree in Civil Engineering (Soil Mechanics and Foundations) from Persian Gulf University in 2015. He attended several conferences and presented some parts of his thesis. 